\title{
Doctoral Studies Carried Out at Botanical Survey of India - Part II
}

\author{
S. Bandyopadhyay ${ }^{1}$, Avishek Bhattacharjee ${ }^{1 *}$, P. Lakshminarashimhan $^{2}$ \\ ${ }^{1}$ Central National Herbarium, Botanical Survey of India, PO Botanic Garden, Howrah, West Bengal, India. \\ ${ }^{2}$ Western Regional Centre, Botanical Survey of India, 7-Koregaon Road, Pune, Maharashtra, India. \\ *Corresponding Author: Avishek Bhattacharjee, Central National Herbarium, Botanical Survey of India, \\ PO Botanic Garden, Howrah, West Bengal, India.Email: avibsi@ rediffmail.com
}

\begin{abstract}
In continuation to the earlier publication (Bandyopadhyay \& Bhattacharjee, 2016) a list of sixty research scholars and staff of Botanical Survey of India who have carried out their doctoral studies at its different units in Howrah and Kolkata and the Regional Centres are provided here.
\end{abstract}

Keywords: Botany, cytogenetics, ethnobotany, floristics, Ph.D., plant chemistry, revision, taxonomy

\section{INTRODUCTION}

Bandyopadhyay and Bhattacharjee (2016) provided a list of forty five research scholars of Botanical Survey of India (BSI), who carried out their doctoral studies at Central National Herbarium $(\mathrm{CNH})$, Howrah, AJC Bose Indian Botanic Garden (AJCBIBG), Howrah, Central Botanical Laboratory (CBL), Howrah and Industrial Section, Indian Museum (ISIM), Kolkata to facilitate the Ph.D. supervisors and researchers of different universities / research institutes to avoid repetition of work while taking up project works on floristics, revisionary or ethnobotanical studies, and also to communicate with the experts to discuss and get valuable opinion in their field of specialization. The present paper is a continuation of Bandyopadhyay and Bhattacharjee's (2016) work, which provides brief information on sixty Ph.D. works carried out by researchers / staff of BSI between 1969 and 2017.

\section{MethodologY}

The methodology followed in this paper is basically the same as in Bandyopadhyay \& Bhattacharjee (2016), but the names of staff who have acquired Ph.D. degree irrespective of the fact that whether they are presently posted at BSI or not have also been included and also the names of the research scholars who have recently submitted their theses for Ph.D. degree are provided. The name of the University from which the Ph.D. has been awarded and the year of obtaining the degree have also been provided.

\section{ENUMERATION}

The details of the sixty research scholars and staff are given as follows:

1. Debika Mitra nee Das

Title of the thesis: 'Taxonomic studies of Indian Annonaceae'. Ph.D. awarded by the University of Calcutta in 1969.

\section{Subir Sen}

Title of the thesis: 'Flora of Hooghly district'. Name of the project: 'Flora of Bhutan'. Period: 19661970. Ph.D. awarded from the University of Calcutta in 1971.

\section{K.V. Billore}

Title of the thesis: 'Studies on the vegetation and flora of Thane district, Maharastra state (India)'. Name of the project: 'Flora of India'. Period: 1966-1971. Ph.D. awarded by the Vikram University, 
Ujjain, Madhya Pradesh in 1973. E-mail: billorekv@gmail.com

\section{Sandhyajyoti Phukan}

Title of the thesis: Revision of the genus Coelogyne Lindl. (Orchidaceae) in India and its vicinity. Name of the project: Flora of India. Period: 1973-1976. Ph.D. awarded by the Gauhati University, Guwahati in 1978. E-mail: sandhyajyotiphukan@yahoo.co.in

\section{Shyamal Kumar Basu}

Title of the thesis: 'Palms of Indian Botanic Garden and vicinity'. Ph.D. awarded from the University of Calcutta in 1980. E-mail: shyamalkbasu@gmail.com

\section{Netra Pal Singh}

Title of the thesis: 'Flora of Eastern Karnataka'. Ph.D. awarded by the Pune University in 1981. Email: netrapal@hotmail.com

\section{A.K. Goel}

Title of the thesis: 'Herbaceous flora of Tehri district (Garhwal)'. Ph.D. awarded by the Hemvati Nandan Bahuguna Garhwal University, Srinagar (Garhwal), Uttarakhand in 1982. E-mail: akgoelofcsirnbri@gmail.com

8. P. Lakshminarasimhan

Title of the thesis: 'Flora of Nasik district'. Name of the project: 'Flora of India'. Period: 1982-1987. Ph.D. awarded by the University of Poona in 1987. E-mail: lakshminarasimhanp@yahoo.co.in

\section{Sandhya Digambar Deshpande}

Title of the thesis: 'Flora of Satara district, Maharashtra state'. Ph.D. awarded by the Pune University in 1988. E-mail: sandhya5.venus@gmail.com

\section{B. C. Sabata}

Title of the thesis: 'Studies on aquatic pollution of River Hooghly (Garden Reach to Vivekanand Bridge)'. Name of the project: 'Assessment of Floristic Diversity in the Protected Areas of India, Phase I: Biosphere Reserves \& National Parks'. Period: 1985-1989. Ph.D. awarded by the Berhampur University, Odisha in 1989. E-mail: bcsabat@yahoo.com

\section{Subir Bandyopadhyay}

Title of the thesis: 'Taxonomic studies on the genus Bauhinia Linn. s.l. (Leguminosae) in India'. Ph.D. awarded by the University of Calcutta in 1992. E-mail: subirbandyopadhyay@yahoo.com

\section{Gopal Prasad Sinha}

Title of the thesis: 'Studies on the lichen flora of Nagaland'. Name of the project: 'Flora India Project: Lichen Flora of Nagaland'. Period: 1984-1989. Ph.D. awarded by the Gauhati University, Guwahati in 1992. E-mail: drgpsinha@gmail.com

\section{G.S. Giri}

Title of the thesis: 'Taxonomic revision of the family Melastomataceae in India'. Ph.D. awarded from the University of Calcutta in 1996. E-mail: girija_ibg@rediffmail.com

14. V.P. Prasad

Title of the thesis: 'A revision of family Cyperaceae in Karnataka, India'. Ph.D. awarded by the Pune University in 1999. E-mail: prasad_parur@yahoo.com

\section{Rajendra Dattu Kshirsagar}

Title of the thesis: 'Ethnobotany of Mysore and Coorg districts, Karnataka state'. Name of the project: 'All India Coordinated research Project on Ethnobiology of Karnataka state. Period: 1995-1998. Ph.D. awarded by the Pune University in 1999. E-mail: drkshirsagar@yahoo.com

\section{Santosh Shankarrao Karne}

Title of the thesis: 'Ethnobotany of Chikmaglur and Dakshin Kannad districts, Karnataka state'. 
Names of the project: 'All India Coordinated research Project on Ethnobiology of Karnataka state'. Period: 1995 -1998. Ph.D. awarded by the Pune University in 1999.

E-mail: toshamika@rediffmail.com

17. Pramod Parasharam Sharma

Title of the thesis: 'Ethnobotany of Dadra Nagar Haveli and Daman'. Name of the project: 'All Indian Coordinated Research Project on Ethnobotany'. Period: 1994-1999. Ph.D. awarded by the Pune University in 1999. E-mail: drppsharma6848@gmail.com

\section{Tapan Seal}

Title of the thesis: 'Studies on plant metabolites of medicinal importance'. Ph.D. awarded by the University of Calcutta in 1999. E-mail: kaktapan65@yahoo.co.in

\section{Dipak Kumar Mishra}

Title of the thesis: 'Studies on Endemic \& threatened flowering plants of Maharashtra'. Name of the project: 'Flora of India'. Period: 1995-2000. Ph.D. awarded by the Pune University in 2000. E-mail: drdipakmishra@yahoo.co.in

\section{Ramesh Kumar}

Title of the thesis: 'Flora of Panna district with special reference to vegetation of diamond mining area'. Ph.D. degree awarded by the Dr. Hari Singh Gour University, Sagar, Madhya Pradesh in 2005. E-mail: rkpaliwalbsi@yahoo.com

\section{Debabrata Maity}

Title of the thesis: 'Vascular plant diversity of Kanchenjunga Biosphere Reserve, Sikkim'. Name of the project: 'Assessment of plant diversity of Kanchenjunga Biosphere Reserve, Sikkim'. Period: 1999-2004. Ph.D. awarded by the University of Kalyani in 2005. E-mail: debmaity @ yahoo.com

\section{Kanad Das}

Title of the thesis: 'Taxo-ecological studies on the family Russulaceae of Kumaon Himalaya'. Name of the project: 'Flora of India'; Period: 1999-2004. Ph.D. awarded by the Hemvati Nandan Bahuguna Garhwal University, Srinagar (Garhwal), Uttarakhand in 2005. E-mail: daskanadbsi@ gmail.com

\section{M. Reema Kumari}

Title of the thesis: 'A Taxonomic Revision of the Indian Solanaceae'. Name of the Project: 'Flora of India'. Period: 1999-2004. Ph.D. awarded by the Bharathiar University, Coimbatore, Tamil Nadu in 2006. E-mail: reemamani@yahoo.com

\section{Sujit Kumar Das Das}

Title of the thesis: 'Studies on Ujani wetland, Maharashtra'. Ph.D. awarded by the Pune University in 2006. E-mail: sujitbsi123@ hotmail.com

\section{Mandar Nilkanth Datar}

Title of the thesis: 'An assessment of floristic diversity of Molem National Park, Goa'. Name of the project: 'Protected Areas Network Programme - Phase I: Biosphere Reserves \& National Parks, India (PAN)'. Period: 2001-2004. Ph.D. awarded by the Pune University in 2007. E-mail: datarmandar@gmail.com

26. J. Jayanthi

Title of the thesis: 'Angiosperm diversity of Campbell Bay National Park, Great Nicobar, India'. Name of the project: 'Assessment of Floristic Diversity in the Protected Areas of India, Phase I: Biosphere Reserves \& National Parks (PAN)'. Period: 2001-2004. Ph.D. awarded by the University of Madras in 2008. E-mail: jayanthi.bsi@gmail.com

\section{Sushil Kumar Singh}

Title of the thesis: 'Morpho-taxonomic studies on Hepaticae (Bryophyta) of the protected areas of Himachal Pradesh - with special reference to National Parks'. Name of the project: 'All India Coordinated Project on Capacity Building in Taxonomy (AICOPTAX)'. Period: 2001-2005. Ph.D. 
awarded by the Hemvati Nandan Bahuguna Garhwal University, Srinagar (Garhwal) in 2007. E-mail: sksbsinc@ rediffmail.com

\section{Chhaya Deori}

Title of the thesis: 'Eco-taxonomy of the genus Dendrobium Sw. (Orchidaceae) of Northeast India'. Ph.D. awarded by the University of Gauhati, Guwahati in 2007. E-mail: drchayadeoribsi@gmail.com

\section{R. Manikandan}

Title of the thesis: 'An assessment of floristic diversity of Rajiv Gandhi National Park, Karnataka'. Name of the project: 'Flora of India'. Period: 1999-2004. Ph.D. awarded by the Pune University in 2008. E-mail: rapamani@gmail.com

\section{Sumathi Ramamurthy}

Title of the thesis: 'Flowering plants of Saddle Peak National Park, North Andamans, India'. Name of the project: 'Flora of India'. Period: 1999-2004. Ph.D. awarded by the University of Madras in 2006. E-mail: sumathi.ramamurthy@gmail.com

\section{Sachin Anil Punekar}

Title of the thesis: 'An assessment of floristic diversity of Anshi National Park, Karnataka'. Name of the project: 'Protected Areas Network Programme - Phase I: Biosphere Reserves \& National Parks, India (PAN)'. Period: 2001-2004. Ph.D. awarded by the Pune University in 2008. E-mail: sachinpunekar@gmail.com

\section{K. Karthigeyan}

Title of the thesis: 'Flowering Plants of Mahatma Gandhi Marine National Park, South Andaman, India'. Name of the project: 'Protected Areas Network Programme - Phase I: Biosphere Reserves \& National Parks, India (PAN)'. Period: 2001-2005. Ph.D. awarded by the University of Madras in 2008. E-mail: karthigeyan.murthy@gmail.com

\section{W. Arisdason}

Title of the thesis: 'Studies on the flora of Indira Gandhi National Park, Southern India'. Name of the project: 'Protected Areas Network Programme - Phase I: Biosphere Reserves \& National Parks, India'. Period: 2001-2004. Ph.D. awarded by the Bharathiar University, Coimbatore, Tamil Nadu in 2008. E-mail: dasonaris@yahoo.co.in

\section{Manas Bhaumik}

Title of the thesis: 'Studies on monocotyledonous plants of Dibang Valley' Ph.D. awarded by the Tilka Manjhi Bhagalpur University, Bhagalpur in 2008. E-mail: dr_manasb@yahoo.com

\section{Mithilesh Kumar Pathak*}

Title of the thesis: 'Studies on dicotyledonous plants of Dibang Valley'. Ph.D. awarded by the Tilka Manjhi Bhagalpur University, Bhagalpur in 2008. *Deceased

\section{Ritesh Kumar Choudhary}

Title of the thesis: 'Floristic diversity of Upper Siang district, Arunachal Pradesh, India'. Name of the project: 'Flora of India'. Period: 2004-2009. Ph.D. awarded by the Rajiv Gandhi University, Itanagar in 2010. E-mail: ritesh.bsi@gmail.com

\section{W. Dinesh Albertson}

Title of the thesis: 'A taxonomic account of tribe Ruellieae (Acanthaceae) in India'. Name of the project: 'Flora of India'. Period: 2003-2008. Ph.D. awarded by the Bharathiar University, Coimbatore in 2011. E-mail: dineshalbertson@gmail.com

\section{Sonali Shripad Piwalatkar}

Title of the thesis: 'Marine Algal Flora of the Maharashtra Coast, India'. Name of the project:

'Flora of India'. Period: 2004-2009. Ph.D. awarded by the Pune University in 2011. E-mail: sonshri76@yahoo.co.in 
39. Mahua Pal

Title of the thesis: 'Study on the Indian members of Convolvulaceae with special reference to their anatomy and their taxonomic importance'. Ph.D. awarded by the University of Kalyani in 2011. Email: mahuapal3@rediffmail.com

\section{C.R. Magesh}

Title of the thesis: 'Studies on the flora of Dalma Wildlife Sanctuary, Jharkhand, India '. Ph. D. awarded by the Bharathiar University, Coimbatore in 2014. E-mail: crmagesh@ rediffmail.com

\section{J.V. Sudhakar}

Title of the thesis: 'A taxonomic revision of the genus Ficus L. (Moraceae) in peninsular India'. Ph.D. awarded by the Bharathiar University, Coimbatore in 2014. E-mail: jvsbsi@yahoo.com

\section{Sujana K. A.}

Title of the thesis: 'A study on taxonomy, ecology and ethnobotany of woody climbers in forests of Wayanad, Kerala'. Ph.D. awarded by the University of Madras in 2014. E-mail: sujanakole@gmail.com

\section{Pankaj Arvind Dhole}

Title of the thesis: 'Studies on some wild edible plant species'. Ph.D. awarded by the Sant Gadge Baba Amravati University, Amravati, Maharashtra in 2014. E-mail: taxonpankaj@gmail.com

\section{C.P. Vivek}

Title of the thesis: 'A taxonomic study on the grass genus Eragrostis Wolf (Tribe: Eragrostideae Stapf) in India'. Name of the project: 'All India Coordinated Project on Capacity Building in Taxonomy' (AICOPTAX). Period: 2010-2015. Ph.D. awarded by Bharathiar University, Coimbatore in 2015. E-mail: vvkcpoulose@gmail.com

\section{G. Gnanasekaran}

Title of the thesis: 'A systematic study on the genus Andrographis Wall. ex Nees (Acanthaceae) in India'. Period: 2011-2015. Ph.D. awarded by the Bharathiar University, Coimbatore in 2015. E-mail: sekaranmcc@gmail.com

\section{Pooja Gupta}

Title of the thesis: 'Lichen Flora of Assam'. Name of the projects: 'All India Coordinated Project on Capacity Building in Taxonomy' (AICOPTAX), 'Flora of India'. Period: 2010-2012, 2013-2018. Ph.D. awarded by the University of Devi Ahilya Vishwavidyalaya, Indore, Madhya Pradesh in 2015. E-mail: poojaguptafri09@gmail.com

\section{Debatri Panja nee Kundu}

Title of the thesis: 'Studies on taxonomy of the tribes Acantheae, Nelsonieae and Thunbergieae (Acanthaceae) in India'. Name of the project: 'Flora of India'. Period: 2003-2008. Ph.D. awarded by the Visva-Bharati University, Santiniketan in 2016. E-mail: debatribsi@gmail.com

\section{Alok R. Chorghe}

Title of the thesis: 'Taxonomy and Distribution of Family Poaceae in Odisha state'. Name of the project: 'Flora of India'. Period: 2010-2015. Ph.D. awarded by the Andhra University, Visakhapatnam in 2016. E-mail: alok.chorghe@gmail.com

\section{Vikas Kumar}

Title of the thesis: 'Taxonomic studies on the tribe Cymbidieae Pfitz. (Orchidaceae) in India'. Name of the projects: 'All India Coordinated Project on Capacity Building in Taxonomy' (AICOPTAX), Project funded by 'Uttarakhand State Council for Science \& Technology' (UCOST): Period: 2010 2012, 2013-2015. Ph.D. awarded by the Kumaun University, Nainital, Uttarakhand in 2016. E-mail: vmadhukar7@gmail.com

\section{Law Kush}

Title of the thesis: 'Taxonomic revision of the subtribe Habenariinae Benth. (Orchidaceae) in India'. 
Name of the project: 'Flora of India'. Period: 2010-2015. Ph.D. degree awarded by the Kumaun University, Nainital, Uttarakhand in 2016. E-mail: awkush_08@rediffmail.com

\section{Gopal Krishna}

Title of the thesis: 'Vascular plant diversity of Buxa National Park, West Bengal, India with special reference to its conservation strategies'. Ph.D. awarded by the University of Calcutta, West Bengal in 2016. E-mail: gopal_bsi@yahoo.co.in

\section{Monika Mishra}

Title of the thesis: 'Studies on induced mutagenesis in Isabgol (Plantago ovata Forssk.)'. Ph.D. awarded by the Aligarh Muslim University, Aligarh, Uttar Pradesh in 2016. E-mail: monikasharma.scholar@gmail.com

\section{Animesh Maji}

Title of the thesis: 'Taxonomic studies on Carex L. occurring in the Eastern Himalaya'. Name of the project: 'Flora of India'. Period: 2013-2018. Ph.D. awarded by the Burdwan University in 2017. Email: animeshmaji11@gmail.com

\section{Bandana Bhattacharjee}

Title of the thesis: Revision of the tribe Vernonieae Cass. (Asteraceae) in India. Name of the project: 'Flora of India'. Period: 2010-2015. Thesis submitted to the University of Kalyani. E-mail: bandanabsi@rediffmail.com

\section{Dyutiparna Chakraborty}

Title of the thesis: 'Taxonomic studies on Boletaceae, Suillaceae, Cantharellaceae, Agaricaceae \& Hygrophoraceae from East \& South districts of Sikkim'. Name of the project: 'Flora of India'. Period: 2013-2018. Thesis submitted to the University of Kalyani in 2017. E-mail: dyuti.parna.mail@gmail.com

\section{Moumita Das Das}

Title of the thesis: 'Taxonomic revision of the family Memecylaceae DC. in India'. Name of the project: 'Flora of India'. Period: 2010-2015. Thesis submitted to the University of Calcutta in 2017. Email: dasdas.moumita10@gmail.com

\section{Shuvadeep Majumdar}

Title of the thesis: 'Taxonomic studies on the Hepaticae and Anthocerotae (Bryophytes) of Anjaw district, Arunachal Pradesh'. Name of the projects: 'All India Coordinated Project on Capacity Building in Taxonomy' (AICOPTAX); 'Flora of India'. Period: 2009-2012, 2013-2018. Thesis submitted to the University of Calcutta in 2017. E-mail: shuvadeep.majumdar@gmail.com

\section{Sutrishna Kar}

Title of the thesis: Taxonomic revision of the genus Festuca L. (Poaceae) in India. Name of the project: 'Flora of India'. Period: 2010-2015. Thesis submitted to the University of Calcutta in 2017. E-mail: me.sutrishna@gmail.com

\section{Durgesh Verma}

Title of the thesis: 'Floristic diversity of some sacred groves and reserve forests of Jaintia hills, Meghalaya'. Thesis submitted to the University of Lucknow in 2017. E-mail: durgesh.kv@ gmail.com

\section{Anant Kumar}

Title of the thesis: 'The flora of the Buxa Wildlife Sanctuary, West Bengal, India'. Thesis submitted to the Andhra University, Visakhapatnam in 2017. E-mail: anantamu@gmail.com

\section{ACKNOWLEDGEMENTS}

We thank Dr. Paramjit Singh, Director, Botanical Survey of India (BSI) and Dr. P.V. Prasanna, Scientist ' $F$ ', Central National Herbarium $(\mathrm{CNH})$, BSI for the facilities. We also thank Dr. A.K. Sahoo, Scientist 'D', BSI, Industrial Section, Indian Museum, Kolkata, Dr. W. Arisdason, Scientist 
'C', CNH, BSI, Dr. K. Karthigeyan, Scientist 'D', CNH and all the then research scholars for providing us the desired information on our request.

\section{REFERENCE}

[1] Bandyopadhyay S. and Bhattacharjee A. Doctoral studies carried out at Botanical Survey of India - Part I. Phytotaxonomy 16, 143-146 (2016 publ. 2017).

Citation: S. Bandyopadhyay et al., " Doctoral Studies Carried Out at Botanical Survey of India Part - II ", International Journal of Advanced Research in Botany, vol. 3, no. 3, p. 8-14, 2017. http://dx.doi.org/10. 20431/2455-4316.0303002

Copyright: (C) 2017 Authors. This is an open-access article distributed under the terms of the Creative Commons Attribution License, which permits unrestricted use, distribution, and reproduction in any medium, provided the original author and source are credited. 